\title{
Structural Analysis of High-Spin States of S0-S4 at OEC Complex: A Theoretical Approach of Small Models
}

\author{
Eduardo W. Castilho-Almeida, ${ }^{a}$ Diego Paschoal, ${ }^{b}$ Hélio F. dos Santos, ${ }^{c}$ \\ Patrick J. O'Malley ${ }^{d}$ and Wagner B. de Almeida*,e \\ ${ }^{a}$ Laboratório de Química Computacional e Modelagem Molecular (LQC-MM), Departamento \\ de Química, ICEx, Universidade Federal de Minas Gerais, Campus Universitário, \\ 31270-901 Belo Horizonte-MG, Brazil \\ ${ }^{b}$ Instituto de Química, Universidade Federal do Rio de Janeiro, Campus Macaé, Avenida Aluizio da \\ Silva Gomes, 50, Granja dos Cavaleiros, 27930-560 Macaé-RJ, Brazil \\ ${ }^{c}$ Núcleo de Estudos em Química Computacional (NEQC), Departamento de Química, ICE, \\ Universidade Federal de Juiz de Fora, Campus Universitário, 36036-330 Juiz de Fora-MG, Brazil \\ ${ }^{d}$ School of Chemistry, University of Manchester, Manchester M13 9PL Lancashire, England, UK \\ eLaboratório de Química Computacional (LQC), Departamento de Química Inorgânica, Instituto de Química, \\ Universidade Federal Fluminense, Campus do Valonguinho, Centro, 24020-141 Niterói-RJ, Brazil
}

\begin{abstract}
S-states at oxygen evolving complex (OEC) are widely studied due to its large importance in photo-oxidation water process. The structural aspects involving S0, S1, S2, S3 and S4 states are still not solved theoretically. Particularly, spin states have been analyzed as an important aspect in S-state models. Seeking to obtain a relevant and simple model to cover high-spin (HS) S0-S4 states we develop a 55-57 atoms model. Through quantum chemical calculations we figured out that our interatomic distance parameters are in agreement with experimental and other theoretical reference values by ca. 10.0 and $3.5 \%$, respectively, being also in good agreement with other theoretical models containing a large number of atoms. Our HS models presented expected oxidation states according to other data on literature for small theoretical models.
\end{abstract}

Keywords: OEC complex, photo-oxidation, S-states, structural analysis, theoretical model

\section{Introduction}

Water and dioxygen are fundamental substances for the maintenance of life as it appears on Earth. These substances provide the minimum conditions for a large part of living organisms maintain their vital functions in the environmental conditions of our planet. The most part of oxygen gas available on nature comes from the photooxidative process of water molecules developed by green plants, algae and cyanobacteria. ${ }^{1-11}$

$$
2 \mathrm{H}_{2} \mathrm{O}_{(1)} \rightarrow \mathrm{O}_{2(\mathrm{~g})}+4 \mathrm{H}_{(\mathrm{aq})}^{+}+4 \mathrm{e}^{-}
$$

As a result of this photochemical process (reaction 1), based on the oxidation of water molecules, we have

*e-mail: wbdealmeida@gmail.com the evolving process of oxygen gas and the energy supply to the maintenance of organisms that carry the Photosystem II (PSII) into their cells. ${ }^{12}$ The reaction 1 is developed in several steps which are catalyzed by PSII-a protein complex found, mainly, in thylakoid membrane from plant chloroplasts or in inner cyanobacteria membrane. ${ }^{4}$

The PSII monomer consists of a cluster of 19 protein subunits, 35 chlorophyll molecules, 2 pheophytin units, $11 \beta$-carotene molecules, more than 20 lipids, 2 plastoquinone, 2 heme irons, 1 non-heme iron, 4 manganese atoms, 3 or 4 calcium atoms, 3 chloride ions, bicarbonate and more than 15 detergents. ${ }^{1,7,9,13,14}$ The PSII is found in photo-dependent organisms in its dimeric form (Figure 1a). Within this protein system we can find an oxygen evolving complex (OEC-Figure 1b) composed of 4 manganese atoms, 4 oxygen atoms and 1 calcium atom $\left(\mathrm{Mn}_{4} \mathrm{CaO}_{5}\right) .^{1-11,13-17}$ This complex constitutes the 


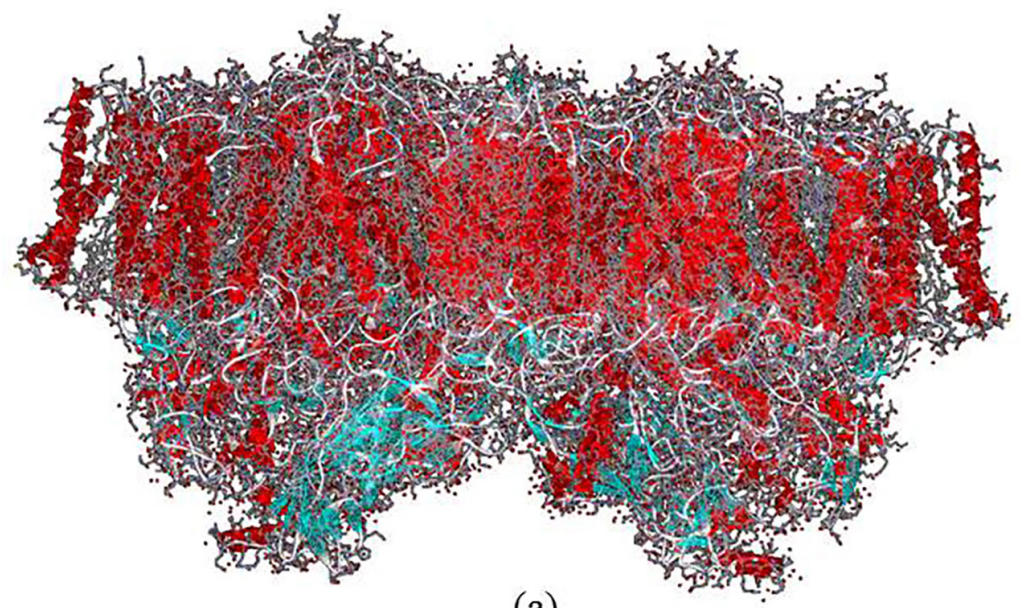

(a)

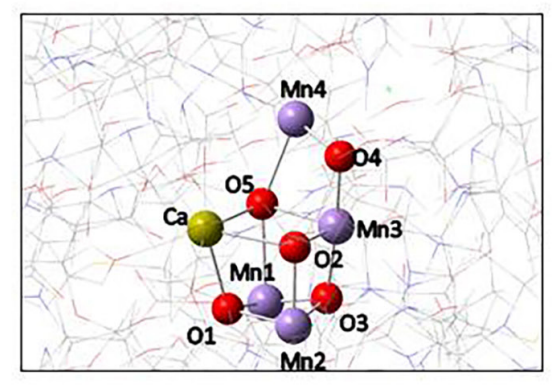

(b)

Figure 1. General structure of PSII dimer from Thermosynechococcus vulcanus cyanobacteria at $1.9 \AA$ (PDB: $3 \mathrm{ARC}$ ) (a) and the OEC (b) present in this protein complex.

target of recent research involving the water oxidation processes in PSII.

The oxygen evolving complex (OEC) has a structure similar to a cubic box with a lid (Figure 1b). In this complex, three manganese atoms are linked to four oxygen atoms $(\mathrm{O} 1, \mathrm{O} 2, \mathrm{O} 3 \mathrm{e} \mathrm{O} 5)$, calcium atom is linked directly to three oxygen atoms (O1, $\mathrm{O} 2$ and $\mathrm{O} 5)$ and another manganese atom outside the cubic box (MnA4) binds to two oxygen atoms ( $\mathrm{O} 4$ and $\mathrm{O} 5)$. The structure highlighted in Figure $1 \mathrm{~b}$ is derived from crystallographic data for PSII at $1.9 \AA$ resolution obtained by Umena et al. ${ }^{9}$ in 2011.

The photosynthetic process leads to the oxygen evolving from oxidation of water molecules located around OEC. However, the process covers a complex serial photo-oxidative reactions induced by light. Reaction begins when the photons ionize the chlorophyll complex $\left(\mathrm{P}_{680}\right)^{1}$ and then, consecutive oxidations occur at tyrosine residue close to OEC (Tyr-Z) and also at the cluster. ${ }^{2}$ The oxidation of water molecules happens according to catalytic cycle proposed by Joliot et al..$^{18}$ and Kok et al. ${ }^{19}$ (Figure 2). At each step in this cycle (S0-S4) the same photo induced process previously presented occurs. As a result, five intermediate states $\left(S_{0}, S_{1}, S_{2}, S_{3}\right.$ and $\left.S_{4}\right)$ are obtained. They differ, basically, in terms of oxidation state of manganese atoms present at OEC.

The most delicate step in molecular modeling of protein parts is to determine a good and representative model. There are several papers in literature considering the OEC cluster according to different approaches. ${ }^{3,6,20,21}$ The main difference among them is related to the cutoff scheme, which is crucial for the choice of the methodology to be used. Recently, several research groups have published important progress in computational modeling of OEC cluster. ${ }^{22-25}$

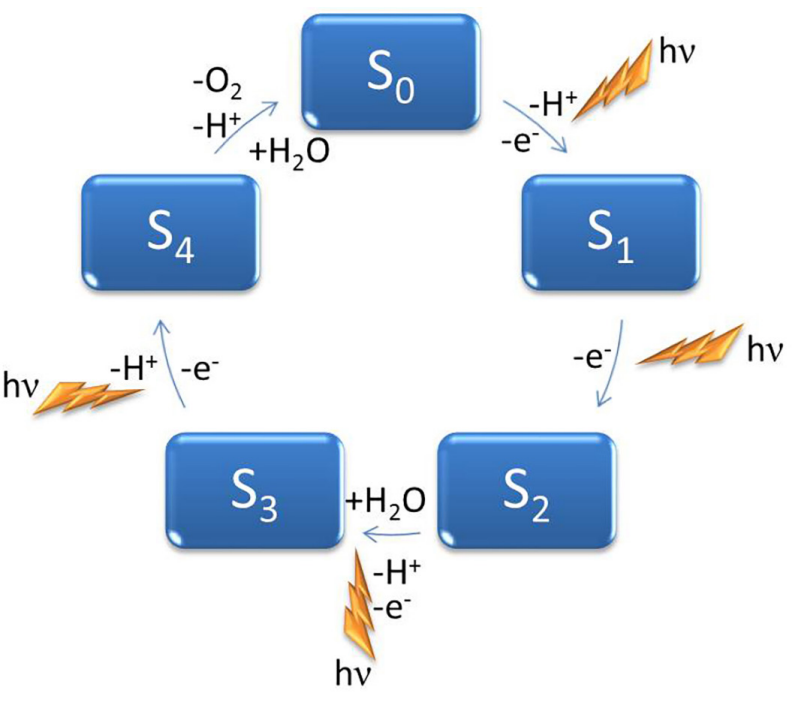

Figure 2. Water photo-oxidative catalytic cycle proposed by Joliot et al..$^{18}$ and Kok et al. ${ }^{19}$

In this work all the calculations were proposed considering a small model of OEC obtained from original PSII crystal structure at $1.9 \AA$ resolution ${ }^{9}$ (PDB code: 3ARC). In this model, only part of the aminoacids residues are linked directly to $\mathrm{CaMn}_{4} \mathrm{O}_{5}$ cluster, and seven water molecules were considered. Thus, beyond the OEC cluster and the 4 water molecules surrounding we have considered in the model: 6 methanoate groups derived from aminoacid residues (Asp342, Asp344, His190, Glu189, Glu333, Glu354) at the first coordination shell and 1 imidazole ring derived from the histidine residue (His332) close to MnD1 atom on cluster. The model considered in all calculations in this work is shown in Figure 3. This study aims to make a contribution to a better understanding of the relation between OEC molecular structure and energy involved in the whole process. Furthermore, we intend to validate 
a small and reliable OEC model to be used in theoretical evaluations of geometrical and electronic structure in different oxidation and spin states.

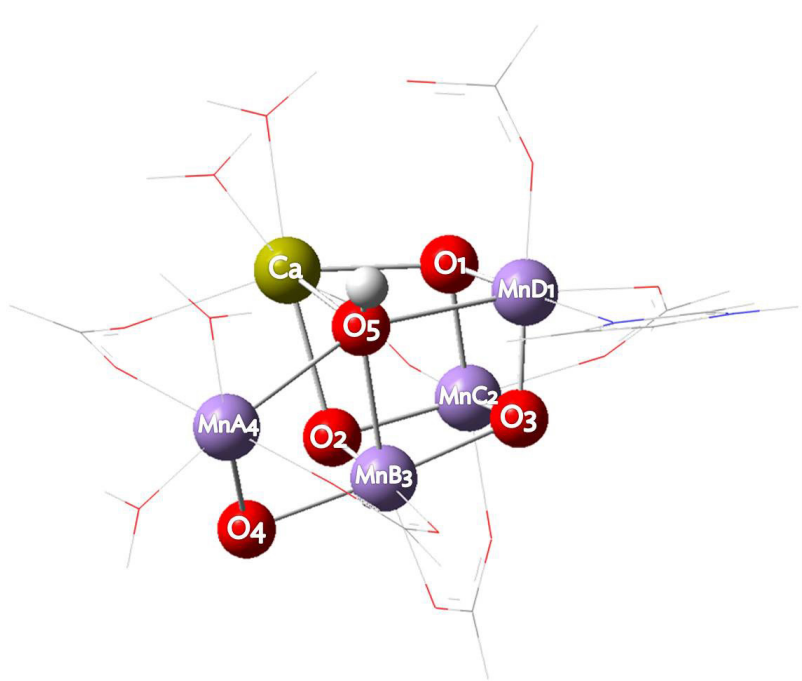

Figure 3. OEC model considered in this work. This is our initial guess based on crystal structure.

\section{Experimental}

The five intermediate states predicted by Joliot $e t$ al. ${ }^{18}$ and Kok et al. ${ }^{19}$ were calculated here considering ground state high spin (HS) structures. This spin scheme was considered in this work once HS OEC structures are well described in literature as the main spin scheme found in natural OEC. . $, 6,26$ We considered initially S0 with zero charge and the following states given in Table 1, according to Kok Cycle scheme, where we can check the different spin/charge arrangements considered in our calculations. For these structures all calculations were performed using the software package Gaussian 09. ${ }^{27}$ The model structures
Table 1. Charges and spin multiplicities considered for S0-S4 models in high-spin (HS) states

\begin{tabular}{lccccc}
\hline Model & S0-HS & S1-HS & S2-HS & S3-HS & S4-HS \\
\hline Charge & 0 & 0 & 1 & 1 & 1 \\
Multiplicity & 16 & 15 & 14 & 13 & 12 \\
\hline
\end{tabular}

were optimized using as input crystal data ${ }^{9}$ considering the amino acids and water molecules with frozen coordinates. All calculations were performed according to ab initio methodology, employing the density functional theory (DFT) method. ${ }^{28-30}$ The B3LYP functional ${ }^{31}$ was used with the $6-31+\mathrm{G}^{*}$ basis set ${ }^{32}$ for carbon, hydrogen and oxygen and the pseudo potential LANL2DZ ${ }^{33}$ for calcium and manganese atoms. From the optimization we can access the Mulliken atomic charges and Mulliken atomic spin densities for each system, which will help us to understand the correlation between the structural parameters and the electronic data.

\section{Results and Discussion}

The structural parameters of theoretical models reported in the literature usually show strong displacements compared to crystal structure. Of course that it is partially related to the limitation of computational methods in mimic high complex PSII structure. However, there are several variables to be considered in this disagreement between experimental and theoretical data. The protonation state of oxygen atoms in OEC, ${ }^{6,34}$ the number of water molecules surrounding $\mathrm{OEC}^{23,35-37}$ and the oxidation and spin state of manganese atoms $s^{38,39}$ are the main issues. In the models studied here all these structural details were considered. As can be seen in Figure 4, the S0 models have one hydrogen atom bound to $\mathrm{O} 5$ in the cluster, which

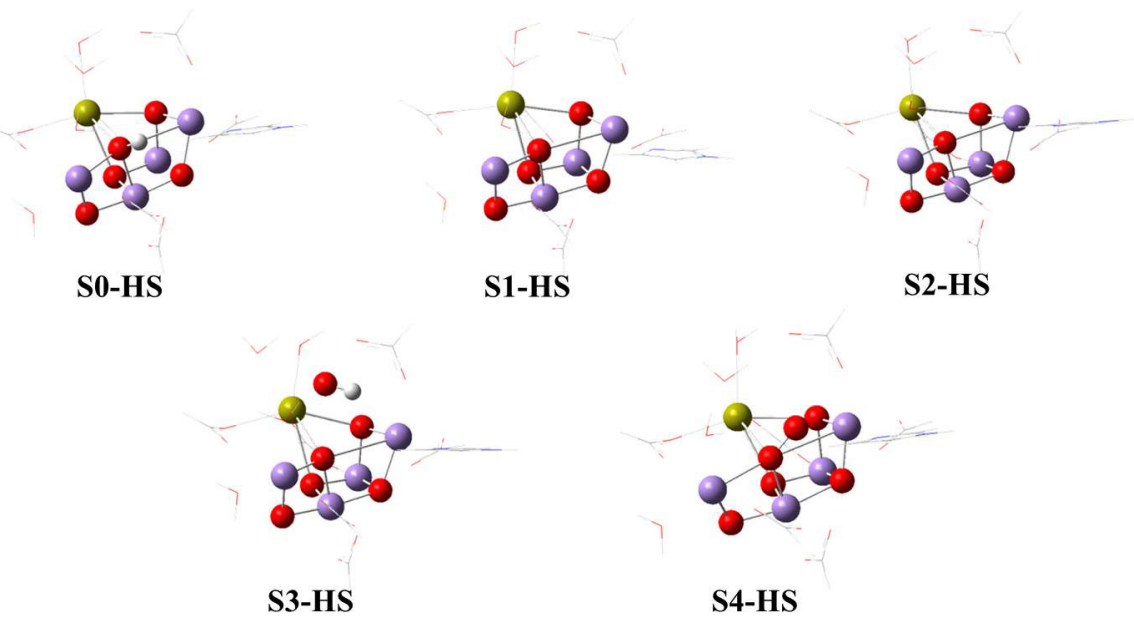

Figure 4. B3LYP/LANL2DZ optimized structures of S-states according to Table 1. 


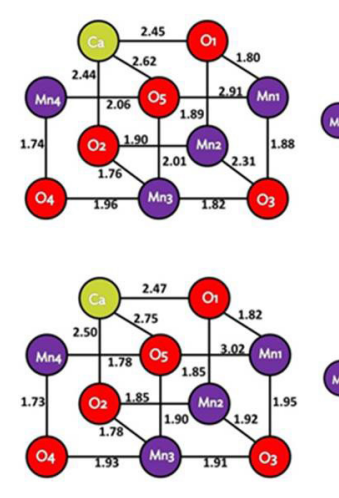

\section{SO-HS}

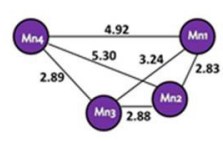

S2-HS
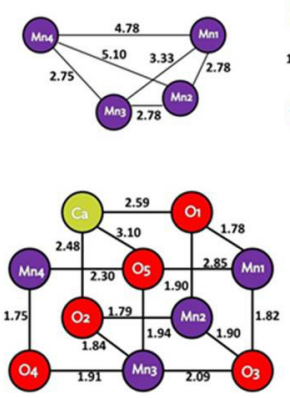

Figure 5. Interatomic distances, in $\AA$, for S-state geometry-optimized DFT models.

drives the structure of other S-states. Moreover, four water molecules were considered in our models. These choices determine geometrical and electronic parameters that will be analyzed below.

All the optimized S0-S4 model structures considering HS are shown in Figure 4. In general, the structural parameters for $\mathrm{Mn}-\mathrm{Mn}, \mathrm{Ca}-\mathrm{O}$ and $\mathrm{Mn}-\mathrm{O}$ are in accordance with theoretical and experimental data (see Figure 5) with minor changes being observed (see Table S1, Supplementary Information section, where the relative percentage deviation of interatomic distances $(\% \Delta)$ among models has been calculated). We have noticed distance displacements between HS models regarding experimental crystal structure (Exp) higher than $20 \%$ for a specific region in OEC. All of them are necessarily related to MnB3, $\mathrm{MnA} 4, \mathrm{O} 3$ and $\mathrm{O} 5$.

In Figure 6 we can verify an interesting behavior involving MnA4-O5 and MnB3-O4 interatomic distances in all HS S-models. For MnA4-O5 parameter S2 models present the worst agreement with experimental value. It represents an under prediction of this parameter in our model. Indeed this fact can be understood once experimental values come from a reduced structure ${ }^{6}$ (obtained by X-ray analysis), ${ }^{9}$ while our model has +1 overall charge. $\mathrm{MnB} 3-\mathrm{O} 4$ parameter, however, present the opposite behavior. This is in accordance with some data from literature. In general, the MnA4-O5 bond is more sensitive to oxidative degree of OEC than MnB3-O4.

Therefore, the OEC region that contains these atoms is usually reported as more sensitive to geometric displacements. ${ }^{5,6,36} \mathrm{It}$ is mainly explained by the $\mu$-oxobridge MnD1---O5---MnA4 that is high sensitive to oxidation and spin state of manganese atoms as reported in literature. . $13,14,36-38,40,41$ The standard structural deviations $(\sigma)$ observed between HS regarding experimental structure is around $10.0 \%$ (see Table S2, Supplementary Information section).

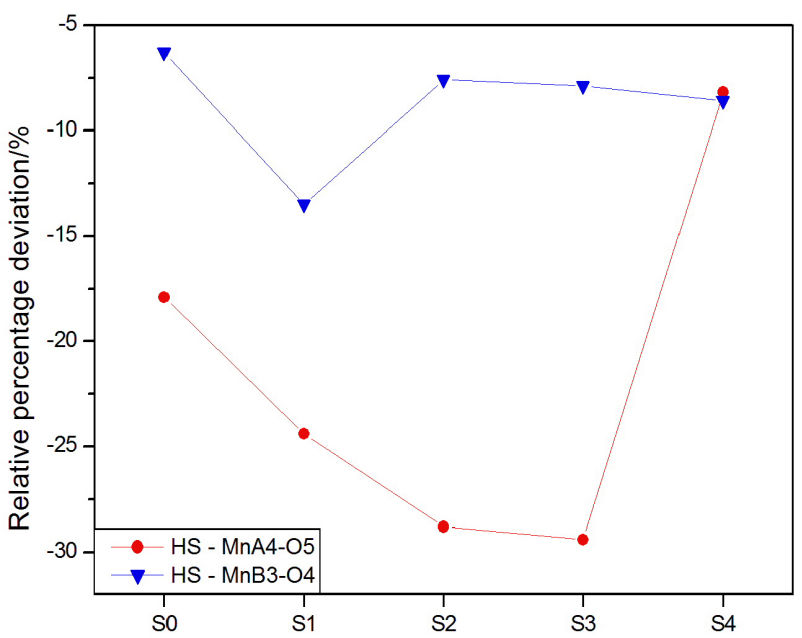

Figure 6. Relative percentage deviation of MnA4-O5 and MnB3-O4 interatomic distance in HS S-states in relation to experimental value (Exp).

The HS calculated models were also compared to reference structure (Ref) from an S2 theoretical model. ${ }^{36}$ It is important to note that the Ref model considered 238 atoms, while our model covered only 55 atoms. From interatomic distance analysis we verified that S2-HS has exhibited the best agreement with Ref value as expected $(\sigma=3.5 \%$, Table 22 , Supplementary Information section). The structural parameters in calculated model are, in general, lower than the same ones from Ref structure. Considering the difference involving the size of calculated and Ref model we have obtained a good agreement in terms 
of structural parameters. The bigger percentage deviation from Ref structure was for MnA4-O4 parameter, $-9.1 \%$ for S2-HS. The structural similarity among S1, S2 and S3, regarding Kok Cycle was also confirmed, which give support to validate our model. Besides, we have noticed a high percentage displacement for $\mathrm{MnC} 2-\mathrm{O} 3$ parameter for S0-HS (see Table S1, Supplementary Information section). Table 2 presents a comparison among different theoretical S2 models and EXAFS and EPR experimental data. ${ }^{38,42}$ Our HS S2 model is the smaller model (55 atoms) and exhibit a similar agreement with experimental interatomic distance values (mainly for EXAFS and EPR data) as well as bigger models ( $>100$ atoms). It can be seen from Table 2 a similar accordance for B3LYP and PB86 DFT functional.

In general terms the oxidation state of manganese atoms at calculated OEC models is in accordance with experimental data $^{38,40,43,44}$ as shown in Table 3. The HS cycle obtained for our models indicates the following pathway to [MnA4, $\mathrm{MnB} 3, \mathrm{MnC} 2, \mathrm{MnD} 1]$ : S0[+3, $+4,+3,+3]$; S1 $[+3,+4,+4$, $+3]$; $\mathrm{S} 2[+4,+4,+4,+3]$; $\mathrm{S} 3[+4,+4,+4,+3]$; $\mathrm{S} 4[+3,+5,+4$, $+4]$. The variation of oxidation state of manganese centers leads to different structural aspects in OEC.$^{38}$ In general, all manganese atoms present tetrahedral distorted geometry (see Figure S1, Supplementary Information section). We have verified that $\mathrm{Mn}^{\mathrm{III}}$, the most common specie in S0-state, usually present two interatomic distances below $2.0 \AA$ with surrounding ligands (oxygen-O, histidine-His, methanoateMet, water-W, hydroxyl-OH and oxygen- $\mathrm{O}_{2}$ ). For S0-HS the $\mathrm{Mn}^{\mathrm{IV}}$ atoms is that with three $\mathrm{Mn}$-ligand interatomic distance below $2.0 \AA$ A. It is a characteristic factor that allows us to understand the oxidation behavior and the structural changes observed in Kok cycle.

The use of hydrogenated O5 instead of pure oxygen leads to a large effect over oxidation state of MnB3, mainly. $\mathrm{MnD} 1$ even being connected to $\mathrm{O} 5$ has not shown any change in oxidation state ( $\mathrm{S} 0$ up to $\mathrm{S} 2$ ). However, for S3 and S4 structure an increase of oxidation state of MnD1 was verified due to a coordination of $\mathrm{MnD} 1$ to $\mathrm{O}_{2}$ molecule. For $\mathrm{MnC} 2$ the oxidation state +3 is related to an increase of $\mathrm{MnC} 2-\mathrm{O} 3$ distance in all models. The pathway to +4 state leads to a $\mathrm{MnC} 2-\mathrm{O} 3$ interatomic distance around $1.9 \AA$ in all models. MnB3, linked to four oxygen in OEC complex,

Table 2. Interatomic distances (in Angstrom) in OEC S2-state according to different theoretical models and experimental data

\begin{tabular}{|c|c|c|c|c|c|c|c|}
\hline \multirow{2}{*}{ Parameter } & \multicolumn{7}{|c|}{ Interatomic distance / $\AA$} \\
\hline & Experimental & $\mathrm{S} 2-\mathrm{HS}^{\mathrm{a}}$ & Reference 36 & Reference 15 & Reference 6 & EXAFS $^{42}$ & $\mathrm{EPR}^{38}$ \\
\hline MnA4-MnB3 & 2.97 & 2.75 & 2.76 & 2.71 & 2.68 & $2.7-2.8$ & 2.7 \\
\hline $\mathrm{MnA} 4-\mathrm{MnC} 2$ & 5.44 & 5.10 & - & - & - & - & - \\
\hline MnA4-MnD1 & 5.00 & 4.78 & - & - & 4.83 & - & - \\
\hline $\mathrm{MnB} 3-\mathrm{MnC} 2$ & 2.89 & 2.78 & 2.80 & 2.78 & 2.76 & $2.7-2.8$ & 2.7 \\
\hline MnB3-MnD1 & 3.29 & 3.33 & 3.40 & 3.29 & 3.35 & 3.2 & 3.3 \\
\hline $\mathrm{MnC} 2-\mathrm{MnD} 1$ & 2.84 & 2.78 & 2.80 & 2.79 & 2.81 & $2.7-2.8$ & 2.7 \\
\hline $\mathrm{Ca}-\mathrm{MnA} 4$ & 3.79 & 3.85 & 4.00 & 3.46 & - & 3.9 & - \\
\hline $\mathrm{Ca}-\mathrm{MnB} 3$ & 3.41 & 3.70 & 3.56 & 3.57 & - & 3.4 & - \\
\hline $\mathrm{Ca}-\mathrm{MnC} 2$ & 3.36 & 3.45 & 3.42 & 3.48 & - & 3.4 & - \\
\hline $\mathrm{Ca}-\mathrm{MnD} 1$ & 3.51 & 3.79 & 3.70 & 3.84 & - & 3.9 & - \\
\hline Atom & - & 55 & 238 & 100 & 105 & - & - \\
\hline Method & - & B3LYP & BP86 & BP86 & BP86 & - & - \\
\hline
\end{tabular}

aPresent work; HS: high-spin.

Table 3. Oxidation states and Mulliken spin densities for manganese atoms in S-state models

\begin{tabular}{|c|c|c|c|c|c|c|c|c|}
\hline & \multicolumn{2}{|c|}{ MnA4 } & \multicolumn{2}{|c|}{ MnB3 } & \multicolumn{2}{|c|}{$\mathrm{MnC} 2$} & \multicolumn{2}{|c|}{ MnD1 } \\
\hline & $\begin{array}{c}\text { Oxidation } \\
\text { state }\end{array}$ & $\begin{array}{c}\text { Spin } \\
\text { density }\end{array}$ & $\begin{array}{c}\text { Oxidation } \\
\text { state }\end{array}$ & $\begin{array}{c}\text { Spin } \\
\text { density }\end{array}$ & $\begin{array}{c}\text { Oxidation } \\
\text { state }\end{array}$ & $\begin{array}{c}\text { Spin } \\
\text { density }\end{array}$ & $\begin{array}{c}\text { Oxidation } \\
\text { state }\end{array}$ & $\begin{array}{c}\text { Spin } \\
\text { density }\end{array}$ \\
\hline S0-HS & +3 & 3.968186 & +4 & 2.989050 & +3 & 3.976954 & +3 & 4.166471 \\
\hline S1-HS & +3 & 3.958831 & +4 & 3.041568 & +4 & 3.105202 & +3 & 4.183617 \\
\hline S2-HS & +4 & 3.064703 & +4 & 3.113213 & +4 & 3.126261 & +3 & 4.147300 \\
\hline S3-HS & +4 & 3.052894 & +4 & 3.093181 & +4 & 3.126589 & +4 & 3.179588 \\
\hline S4-HS & +4 & 3.083799 & +5 & 1.979354 & +4 & 3.084581 & +4 & 3.296178 \\
\hline
\end{tabular}

HS: high-spin. 
Table 4. UB3PW91/TZ2P-DKH/Def2-SVP//UB3LYP/LANL2DZ/6-31+G(d) ${ }^{55} \mathrm{Mn}$ isotropic hyperfine coupling (Aiso in MHz) for manganese atoms in S-state models

\begin{tabular}{lcccccc}
\hline \multirow{2}{*}{ Model } & Charge & Multiplicity & \multicolumn{3}{c}{${ }^{55} \mathrm{Mn} \mathrm{Aiso}^{\mathrm{a}} / \mathrm{MHz}$} \\
\cline { 4 - 7 } & & & MnD1 & MnC2 & MnB3 & MnA4 \\
\hline S0-HS & 0 & 16 & -32.67 & -41.21 & -35.33 & -63.04 \\
S1-HS & 0 & 15 & -30.12 & -30.59 & -25.95 & -41.54 \\
S2-HS & 1 & 14 & -39.92 & -32.75 & -25.28 & -42.35 \\
S3-HS & 1 & 13 & -45.17 & -35.02 & -26.77 & -44.60 \\
S4-HS & 1 & 12 & -46.06 & -38.52 & -44.82 & -38.60 \\
\hline
\end{tabular}

HS: high-spin; avalues scaled by a factor of 1.085 , obtained to reproduce the experimental data of $-245 \mathrm{MHz}$ for $\left[\mathrm{Mn}\left(\mathrm{H}_{2} \mathrm{O}\right)_{6}\right]^{+2}(\mathrm{~S}=5 / 2)$ complex..$^{45}$

increase the oxidation level from +4 to +5 as the $\mathrm{MnB} 3-\mathrm{O} 5$ distance decrease. This manganese atom shows the highest oxidation state in OEC model. Finally, for MnA4 the change from oxidation state +3 to +4 implies a decrease of MnA4-O5 length. The oxidation state verified for our calculated models are in agreement with recent theoretical data available in literature. ${ }^{44}$

Hyperfine coupling data are known to provide relevant information of electron paramagnetic resonance (EPR) spectrum of the OEC since they are sensitive to the spin density distribution at a nucleus in molecular systems, yielding information about electronic structure and also can be used to validate proposed structural models. In an attempt to verify the influence of the OEC model structures on the ${ }^{55} \mathrm{Mn}$ isotropic hyperfine coupling (Aiso) DFT calculations were performed for the four manganese atoms in S-state models (HS). To calibrate our calculations we first carried out isotropic hyperfine coupling (Aiso) DFT calculations for high-spin $\left[\mathrm{Mn}\left(\mathrm{H}_{2} \mathrm{O}\right)_{6}\right]^{2+}$ $(\mathrm{S}=5 / 2)$ complexes, where experimental data and other theoretical result are available. The sensitivity to the level of calculation and basis set was quite remarkable. The UB3LYP/LANL2DZ/6-31+G(d) results was close to zero, in disagreement with the experimental data of $-245 \mathrm{MHz},{ }^{45}$ as a result of pseupotentials lack of density at nucleus. The UB3PW91/Def2-QZVPP/Def2-SVP/UB3LYP/ LANL2DZ/6-31+G(d) and UB3PW91/TZ2P-DKH/ Def2-SVP//UB3LYP/LANL2DZ/6-31+G(d) single point calculations results indicated by the double slash, with the UB3LYP/LANL2DZ/6-31+G(d) optimized geometries, are respectively -185 and $-226 \mathrm{MHz}$, with the last one being in better agreement with experiment than a previously DFT reported value of $-196 \mathrm{MHz}$ by Remenyi et al. ${ }^{46}$ using a different methodology. We chose the UB3PW91/ TZ2P-DKH/Def2-SVP level of calculation, with a scaling factor of 1.085 to reproduce the experimental data for the $\left[\mathrm{Mn}\left(\mathrm{H}_{2} \mathrm{O}\right)_{6}\right]^{2+}$ complex, to be used in the OEC model Aiso calculations. The DFT ${ }^{55} \mathrm{Mn}$ Aiso (in $\mathrm{MHz}$ ) results for the four manganese atoms specified in Figure 3 are given in
Table 4. Aiso is proportional to the electron spin density at the nucleus and so the values reported in Table 4 show that the larger spin density at each Mn nucleus can vary significantly with the S-state model used. Our results indicated that the MnA4 atom in the S0-HS model exhibited the largest hyperfine coupling value with the highest accumulation of spin density among the four manganese atoms.

\section{Conclusions}

From our HS calculated models we have analyzed several structural remarkable aspects in OEC. By DFT geometry optimization of S0-S4 OEC states we found some structural deviations in comparison with experimental (around 10.0\%) and theoretical reference data (around $3.5 \%$ for S2 model). The good agreement between small models considered in the present work (55-57 atoms) with other theoretical studies involving larger models, regarding structural data, validate our approach which is computationally much more viable.

The interatomic distances involving MnA4, MnB3, $\mathrm{O} 3$ and $\mathrm{O} 5$ have presented the largest relative percentage deviation. It is in accordance with several references on literature. The large deviations observed for MnA4-O5 regarding experimental values were understood due to overall +1 charge considered in calculated models instead of negative overall charge related to X-ray measurement (causes OEC reduction).

The analysis of oxidation and spin states of HS models allow us to estimate oxidation process behavior according to structural displacements. The predicted oxidation states for manganese atoms were in agreement with theoretical analysis for small models. ${ }^{44}$

Finally, by comparing the B3LYP results obtained with our HS small model structures with existing data in the literature it can be concluded that the molecular structures proposed in this work to represent the OEC can be considered adequate to be used in further related theoretical 
studies at an affordable computational cost. In addition, a computational affordable DFT level of calculation to be used in the evaluation of ${ }^{55} \mathrm{Mn}$ isotropic hyperfine coupling values for OEC model systems was determined which may be useful in further theoretical investigations.

\section{Supplementary Information}

Supplementary information (Tables S1 and S2 and Figure S1) is available free of charge at http://jbcs.sbq.org.br as a PDF file.

\section{Acknowledgments}

E. W. Castilho-Almeida would like to thank FAPEMIG (Fundação de Amparo a Pesquisa no Estado de Minas Gerais) for a Post-Doctoral scholarship. We also thank the University of Manchester Computer Share Facilities (CSF) for providing computational resources to develop part of this work. H. F. dos Santos and W. B. de Almeida thank the Brazilian Agencies CNPq, CAPES and FAPEMIG for their continuing support of our laboratories.

\section{References}

1. Manchanda, R.; Brudvig, G. W.; Crabtree, R. H.; Coord. Chem. Rev. 1995, 144, 1.

2. Robblee, J. H.; Cinco, R. M.; Yachandra, V. K.; Biochim. Biophys. Acta 2001, 1503, 7 .

3. Sproviero, E. M.; Mcevoy, J. P.; Brudvig, G. W.; Batista, V. S.; J. Chem. Theory Comput. 2006, $2,1119$.

4. Sproviero, E. M.; Gascón, J.; McEvoy, J. P.; Brudvig, G. W.; Batista, V. S.; J. Am. Chem. Soc. 2008, 130, 3428.

5. Pantazis, D. A.; Orio, M.; Petrenko, T.; Zein, S.; Lubitz, W.; Messinger, J.; Neese, F.; Phys. Chem. Chem. Phys. 2009, 11, 6788.

6. Ames, W.; Pantazis, D. A; Krewald, V.; Cox, N.; Messinger, J.; Lubitz, W.; Neese, F.; J. Am. Chem. Soc. 2011, 133, 19743.

7. Kawakami, K.; Umena, Y.; Kamiya, N.; Shen, J.-R.; J. Photochem. Photobiol., B 2011, 104, 9.

8. Luber, S.; Rivalta, I.; Umena, Y.; Kawakami, K.; Shen, J.-R.; Kamiya, N.; Brudvig, G. W.; Batista, V. S.; Biochemistry 2011, $50,6308$.

9. Umena, Y.; Kawakami, K.; Shen, J.-R.; Kamiya, N.; Nature 2011, 473, 55.

10. Gatt, P.; Petrie, S.; Stranger, R.; Pace, R. J.; Angew. Chem. 2012, $124,12191$.

11. Klauss, A.; Haumann, M.; Dau, H.; Proc. Natl. Acad. Sci. USA 2012, 109, 16035.

12. Siegbahn, P. E. M.; J. Photochem. Photobiol., B 2011, 104, 94.
13. Yano, J.; Kern, J. In Encyclopedia of Inorganic and Bioinorganic Chemistry; John Wiley and Sons: Hoboken, 2012.

14. Galstyan, A.; Robertazzi, A.; Knapp, E. W.; J. Am. Chem. Soc. 2012, 134, 7442.

15. Cox, N.; Rapatskiy, L.; Su, J.-H.; Pantazis, D. A.; Sugiura, M.; Kulik, L.; Dorlet, P.; Rutherford, A. W.; Neese, F.; Boussac, A.; Lubitz, W.; Messinger, J.; J. Am. Chem. Soc. 2011, 133, 3635.

16. Najafpour, M. M.; J. Photochem. Photobiol., B 2011, 104, 111.

17. Siegbahn, P. E. M.; ChemPhysChem 2011, 12, 3274.

18. Joliot, P.; Barbieri, G.; Chabaud, R.; Photochem. Photobiol. 1969, 10, 309.

19. Kok, B.; Forbush, B.; McGloin, M.; Photochem. Photobiol. 1970, 11, 457.

20. Ichino, T.; Yoshioka, Y.; Chem. Phys. Lett. 2014, 595-596, 237.

21. Yamaguchi, K.; Isobe, H.; Yamanaka, S.; Saito, T.; Kanda, K.; Shoji, M.; Umena, Y.; Kawakami, K.; Shen, J.-R.; Kamiya, N.; Okumura, M.; Int. J. Quantum Chem. 2013, 113, 525.

22. Kurashige, Y.; Chan, G. K.-L.; Yanai, T.; Nat. Chem. 2013, 5, 660.

23. Siegbahn, P. E. M.; Biochim. Biophys. Acta 2013, 1827, 1003.

24. Li, X.; Siegbahn, P. E. M.; Phys. Chem. Chem. Phys. 2015, 17, 12168.

25. Retegan, M.; Krewald, V.; Mamedov, F.; Neese, F.; Lubitz, W.; Cox, N.; Pantazis, D. A.; Chem. Sci. 2016, 7, 72.

26. Pantazis, D. A.; Orio, M.; Petrenko, T.; Zein, S.; Bill, E.; Lubitz, W.; Messinger, J.; Neese, F.; Chemistry 2009, 15, 5108.

27. Frisch, M. J.; Trucks, G. W.; Schlegel, H. B.; Scuseria, G. E.; Robb, M. A.; Cheeseman, J. R.; Scalmani, G.; Barone, V.; Mennucci, B.; Petersson, G. A.; Nakatsuji, H.; Caricato, M.; Li, X.; Hratchian, H. P.; Izmaylov, A. F.; Bloino, J.; Zheng, G.; Sonnenberg, J. L.; Hada, M.; Ehara, M.; Toyota, K.; Fukuda, R.; Hasegawa, J.; Ishida, M.; Nakajima, T.; Honda, Y.; Kitao, O.; Nakai, H.; Vreven, T.; Montgomery, J. A.; J.; Peralta, J. E.; Ogliaro, F.; Bearpark, M.; Heyd, J. J.; Brothers, E.; Kudin, K. N.; Staroverov, V. N.; Kobayashi, R.; Normand, J.; Raghavachari, K.; Rendell, A.; Burant, J. C.; Iyengar, S. S.; Tomasi, J.; Cossi, M.; Rega, N.; Millam, N. J.; Klene, M.; Knox, J. E.; Cross, J. B.; Bakken, V.; Adamo, C.; Jaramillo, J.; Gomperts, R.; Stratmann, R. E.; Yazyev, O.; Austin, A. J.; Cammi, R.; Pomelli, C.; Ochterski, J. W.; Martin, R. L.; Morokuma, K.; Zakrzewski, V. G.; Voth, G. A.; Salvador, P.; Dannenberg, J. J.; Dapprich, S.; Daniels, A. D.; Farkas, Ö.; Foresman, J. B.; Ortiz, J. V.; Cioslowski, J.; Fox, D. J.; Gaussian, Inc.; Wallingford, CT, 2009.

28. Kohn, W.; Becke, D.; Parr, R. G.; J. Phys. Chem. 1996, 100, 12974.

29. Hohenberg, P.; Kohn, W.; Phys. Rev. B 1964, 136, B864.

30. Kohn, W.; Sham, L. J.; Phys. Rev. 1965, 140, 1133.

31. Lee, C.; Yang, W.; Parr, R. G.; Phys. Rev. B 1988, 37, 785.

32. Hehre, W. J.; Radom, L.; Schleyer, P. V. R.; Pople, J. A.; Ab initio Molecular Orbital Theory; Wiley: New York, 1986, p. 576. 
33. Hay, P. J.; Wadt, W. R.; J. Chem. Phys. 1985, 82, 299.

34. Siegbahn, P. E. M.; Inorg. Chem. 2008, 47, 1779.

35. Rapatskiy, L.; Cox, N.; Savitsky, A.; Ames, W. M.; Sander, J.; Nowaczyk, M. M.; Rögner, M.; Boussac, A.; Neese, F.; Messinger, J.; Lubitz, W.; J. Am. Chem. Soc. 2012, 134, 16619.

36. Lohmiller, T.; Krewald, V.; Navarro, M. P.; Retegan, M.; Rapatskiy, L.; Nowaczyk, M. M.; Boussac, A.; Neese, F.; Lubitz, W.; Pantazis, D.; Cox, N.; Phys. Chem. Chem. Phys. 2014, 16, 11877.

37. Cox, N.; Pantazis, D. A.; Neese, F.; Lubitz, W.; Acc. Chem. Res. 2013, 46, 1588.

38. Brynda, M.; Britt, D. In Biological Magnetic Resonance: Applications of high Resolution EPR to Metalloenzymes, vol. 29; Hanson, G.; Berliner, L., eds.; Springer: New York, 2010, p. 203.

39. Haddy, A.; Photosynth. Res. 2007, 92, 357.

40. Bovi, D.; Narzi, D.; Guidoni, L.; Angew. Chem. 2013, 125, 11960.
41. Yamaguchi, K.; Yamanaka, S.; Isobe, H.; Saito, T.; Kanda, K.; Umena, Y.; Kawakami, K.; Shen, J.-R.; Kamiya, N.; Okumura, M.; Nakamura, H.; Shoji, M.; Yoshioka, Y.; Int. J. Quantum Chem. 2013, 113, 453.

42. Pushkar, Y.; Yano, J.; Glatzel, P.; Messinger, J.; Lewis, A.; Sauer, K.; Bergmann, U.; Yachandra, V.; J. Biol. Chem. 2007, 282, 7198.

43. O’Malley, P. J.; J. Phys. Chem. A 1997, 101, 9813.

44. Krewald, V.; Retegan, M.; Cox, N.; Messinger, J.; Lubitz, W.; DeBeer, S.; Neese, F.; Pantazis, D. A.; Chem. Sci. 2015, 6, 1676.

45. Upreti, G. C.; J. Magn. Reson. 1974, 13, 336.

46. Remenyi, C.; Reviakine, R.; Arbuznikov, A. V.; Vaara, J.; Kaupp, M.; J. Phys. Chem. A 2004, 108, 5026.

Submitted: April 6, 2016 Published online: June 1, 2016 